\title{
Bastardos e órfãos contemporâneos: a arqueologia da infância nos romances de filiação
}

Alessandra Dalva de Souza Pajolla ${ }^{1}$

\section{A infância e a fabricação identitária}

O teórico francês Dominique Viart (2008) destaca a proliferação do tema familiar na literatura contemporânea. A reconstituição das origens configura uma dinâmica narrativa presente em diversas obras: o retorno ao passado despido de nostalgia, marcado pela tentativa de explicar por meio das origens (reais e imaginárias) as lacunas identitárias. Os romances de filiação integram essa tendência e interrogam a ascendência como um mecanismo para resolver enigmas do presente.

O início dos anos 1980 é concebido por Viart (2008) como o marco de um período caracterizado pelo fracasso das vanguardas e das ideologias, resultando na reabilitação do sujeito à cena literária, no retorno às narrativas do "eu". Desdobrada em variações autobiográficas, romances familiares e genealógicos, a narrativa contemporânea investe em uma investigação inquietante, conduzida por indivíduos incertos, que procuram em sua ascendência e nas memórias, sobretudo da infância, uma parte obscura de suas verdades singulares, suas identidades.

O romance de filiação se desenvolve no cruzamento de gêneros romance familiar e romance genealógico - sob a forma de ficções biográficas ou não. As obras expõem o percurso de personagens que escavam as origens em busca de uma espécie de herança recebida sem testamento, sujeitos que se sentem afetados por circunstâncias ligadas à genealogia e a partir daí empreendem deslocamentos geográficos e temporais em busca de autoconhecimento e pertencimento.

A infância é o espaço da memória, revisitada e reinventada por narradores à procura de segredos sepultados, que tentam reorganizar imagens fragmentadas e encontrar respostas para os conflitos identitários do presente. A figura do bastardo e do órfão são representações comuns nesses romances, encenando os conflitos entre herança e transmissão, genealogias e afinidades, semelhanças e

\footnotetext{
${ }^{1}$ Doutoranda em estudos literários pela Universidade Estadual de Maringá (UEM), Maringá, PR, Brasil. E-mail: alepajolla@ hotmail.com
} 
singularidades. Um percurso que questiona o paradigma genealógico e os processos de fabricação identitária.

Em Era meu esse rosto (2012), de Marcia Tiburi, dois planos narrativos se alternam com diferentes perspectivas temporais. O primeiro é o relato da incursão do narrador, em idade adulta, por Veneza, com o objetivo de reconstituir a origem do avô paterno e, com isso, preencher a própria lacuna identitária. $O$ segundo é o plano da infância, no interior do Rio Grande do Sul, quando o menino, filho ilegítimo, fora integrado por esse avô à família. "Sou apenas eu quando me esqueço onde estou e tenho sete anos perdido nessa habitação opaca que é a memória" (Tiburi, 2012, p. 35), diz o narrador.

A ideia de uma marca que se adquire ao nascer, como se o fator biológico distinguisse ou definisse as pessoas por meio da semelhança, é descontruída em Azul-corvo (2010), de Adriana Lisboa. A obra narra o percurso da personagem Vanja, uma menina de 13 anos, em busca do pai biológico. Ela contará com ajuda de Fernando, que até então era apenas um "pai" arranjado, que cumprira a formalidade no registro de nascimento. A menina espera encontrar as raízes e os galhos que faltam em sua árvore genealógica, mas terminará por se reconhecer em um modelo diferente de árvore, baseado em afinidades.

Eu tinha treze anos. Ter treze anos é como estar no meio de lugar nenhum. $\mathrm{O}$ que se acentuava devido ao fato de eu estar no meio de lugar nenhum. Numa casa que não era minha, num país que não era o meu, com uma família de homem só que não era, apesar das intenções (todas elas muito boas), minha (Lisboa, 2010, p. 12).

Essa ideia da infância como um "meio de lugar nenhum", acentuada por uma genealogia confusa, também está presente em Chove sobre minha infância (2012), de Miguel Sanches Neto, uma autoficção. O personagem que narra é o próprio autor, que logo no início esclarece que não se trata de uma obra de memórias, mas de "retalhos". E adverte o leitor de que alguns deles são falsificados pela recordação e pela fantasia. A narrativa é um diálogo entre o menino e o adulto, por meio do mergulho no ambivalente processo de identificação com os "dois pais" completamente diferentes: o biológico, que ele mal conheceu, e o padrasto, com quem teve uma relação conflituosa.

Nota-se, nos três romances, a preocupação arqueológica mencionada por Laurent Demanze (2008) como característica dos romances de filiação. O objetivo é escavar os vestígios do passado à procura de uma parte do 
"eu", como se algo não realizado assombrasse os tempos atuais. "Herdeiro problemático, o escritor contemporâneo constrói as narrativas de filiação para exumar os vestígios de um patrimônio em ruínas e juntar os pedaços fragmentados de sua memória" (Demanze, 2008, p. 9, tradução nossa).

\section{A criança perdida e o bastardo}

Era meu esse rosto (2012) é o quarto romance da filósofa e escritora Marcia Tiburi e apresenta uma leitura contemporânea da figura do bastardo. Dois planos narrativos se alternam: o da infância, pontuado por uma memória fragmentada, real e imaginária; e o da fase adulta, no momento em que o narrador personagem parte em sua busca pelas origens do avô materno. A obra também possui características do romance familiar freudiano, trazendo luz à ficção criada pela criança, misturando fantasia e realidade na tentativa de configurar a própria identidade.

Em 1909, Sigmund Freud publicou o artigo "O romance familiar dos neuróticos", enfocando a fabricação identitária empreendida na infância, quando as crianças, ao se decepcionarem com os pais, inventam uma família substituta. O romance familiar se enraíza em uma dupla perda: o medo de perder o amor dos pais e a decepção que as crianças sofrem ao perceberem que eles não são deuses, nem heróis. Elas passam a construir narrativas fantasmáticas para corrigir a realidade e fazer o medo desaparecer.

A ficção se torna uma ferramenta na construção da identidade, sendo comum a fantasia com a figura dos bastardos, que partem em busca daqueles que seriam seus verdadeiros pais e que teriam uma origem nobre. As imagens que povoam o romance familiar vêm da mesma fonte: os contos ou mitos com os quais a criança toma contato na infância. Essa operação envolve uma bricolagem, porque a criança se mistura às leituras, reconfigurando as histórias com fragmentos da realidade.

Partindo das ideias de Freud, Marthe Robert publicou em 1972 a obra Romance das origens e origem dos romances. ${ }^{2}$ Segundo a estudiosa francesa, o romance familiar é o lugar da criação ficcional, construída em torno da dialética entre duas figuras: de um lado a "criança perdida" e seu mundo de sonho e, de outro, o "bastardo", que deseja conquistar o real.

\footnotetext{
${ }^{2}$ A edição utilizada como referência neste artigo foi publicada em 2007.
} 
A autora define o romance familiar como um expediente da imaginação para resolver a crise típica do crescimento humano. Obrigada a ir adiante, mas incapaz de renunciar ao paraíso que, apesar de tudo, ainda julga eterno, a criança refugia-se num mundo mais dócil. Ela escolhe sonhar. É assim que passa a inventar histórias, um arranjo tendencioso da sua fábula biográfica, concebido para explicar a vergonha de ser malnascida, desfavorecida, mal-amada; e que lhe é oferecido também o recurso de se lamentar, se consolar e se vingar num mesmo movimento da imaginação (2007, p. 36).

Para compor a trama de seu "romance familiar", a criança não precisa, aliás, de um logro muito complicado, bastando-lhe transferir para o âmbito de um fato externo a mudança toda interna cujos motivos permanecem-lhes ocultos: irreconhecíveis a seus olhos a partir do momento em que lhes descerra um rosto humano, seus pais lhe parecem tão mudados que ela não consegue mais reconhecer como seus, concluindo daí que não são verdadeiros pais, mas literalmente estranhos, pessoas quaisquer com as quais nada tem em comum a não ser o fato de a terem recolhido e educado (Robert, 2007, p. 37).

Vendo-se como uma criança perdida, abandonada ou adotada, a criança encontra uma razão para o sentimento de estranheza que agora lhe inspiram os pais, destituídos do posto de heróis. Ela acredita que um dia toda essa história se revelará e sua verdadeira família, nobre ou poderosa, a reintegrará a seu lugar de origem.

Em Era meu esse rosto (2012), os dois personagens centrais, o narrador e o avô, têm em comum a bastardia. $\mathrm{O}$ avô fora deixado na roda de um convento na Itália e depois fora adotado e trazido para o Brasil. O narrador, por sua vez, é um filho ilegítimo, que deixara a condição miserável em que vivia graças à intervenção do avô. "Meu avô me leva consigo, não sem antes dar dinheiro, riqueza e miséria, contos de réis à minha mãe que agradece sem olhar-me" (Tiburi, 2012, p. 132).

Os dois personagens, unidos pela bastardia e pela angústia em relação às origens, estabelecem uma forte conexão. $\mathrm{O}$ menino acredita que o avô tem uma origem nobre e quando adulto embarcará para a Itália para tentar decifrar essa ascendência.

As duas correntes apontadas por Robert (2007) no romance familiar o "bastardo realista" e a "criança perdida" - são reproduzidas na obra de Tiburi por meio dos dois planos narrativos. Enquanto a "criança 
perdida" mistura fantasia e realidade, representada pela infância e memórias do personagem, o "bastardo realista" é consciente de sua condição e decide enfrentá-la. Não lhe bastam provas documentais, o personagem busca aquilo o que não lhe foi possível na infância: reconhecer-se na árvore genealógica à qual supostamente faz parte.

Como não havia fotografias em casa, o menino fantasia as semelhanças e é obcecado por imagens, a ponto de se tornar fotógrafo na fase adulta. Essa procura só terá fim quando finalmente encontrar um rosto que dará materialidade à fabricação identitária: a fotografia de um bebê no cemitério de Veneza, no túmulo de sua suposta avó biológica. O personagem toma como seu o rosto que seria do avô.

\section{Desconstruindo o paradigma genealógico}

A ideia de semelhanças a partir da genealogia é colocada em xeque nos romances de filiação contemporâneos. Françoise Noudelmann (2004) destaca que a palavra genealogia atribui uma ordem, fornece um discurso. Legitima a posse de um território, define um patrimônio genético ou cultural. Naturaliza as posições simbólicas, eterniza os poderes adquiridos, estabelece classificações e a repetição dentro da família em que se desenham as figuras de filiação e de transmissão. Hereditariedade, herança são noções que supõem apropriações retrospectivas ou prospectivas que identificam uma propriedade ("filho ou filha de"), inventam e reconduzem legitimidades (Noudelmann, 2004, p. 12).

O narrador/autor de Chove sobre minha infância (2012) perde o pai cedo, mas carregará por toda a infância o peso de uma transmissão hereditária compulsória. "Sempre tive que pagar o preço de ter um sobrenome espanhol. Minha ascendência explicava todos os meus defeitos de caráter. Briguento, irritadiço, violento, orgulhoso, teimoso" (Sanches Neto, 2012, p. 16). "Filho do pai", diziam os vizinhos, referindo-se ao pai que ele mal conheceu e reforçando a imagem à qual o menino se esforçará para corresponder.

Perseguindo a figura idealizada do pai morto, o menino tenta construir a sua identidade à luz do que acredita ser uma herança genética. Assume comportamentos que desafiam o padrasto, um homem simples, da roça. No lugar do trabalho braçal, Miguel refugia-se nos livros e vive uma infância difícil, num constante entremundos que lhe dá permanente sensação de deslocamento. 
De modo que esse sentimento de orfandade que sempre me marcou vai se estendendo para todos os lados. Não me reconheço na família, nem no colégio, e nem na cidade. Isso me empurra, cada vez mais, a buscar o meu domínio, o meu território, que não sei ainda bem qual é. Leio para tentar descobrir o meu lugar nisso tudo, nesse troço estranho que chamam de vida (Sanches Neto, 2012, p. 160).

A crítica genealógica, observa Noudelmann (2004), serve para desnudar o discurso que funciona sobre os conceitos universais que apagam suas condições de produção. No lugar de eternizar a permanência, a universalidade, essa abordagem revela o trabalho do imaginário inerente a toda representação. A finalidade é descobrir seus modelos operatórios, procedimentos de reconhecimento e validação de códigos e valores, as matrizes e as articulações sobre as quais a coletividade agencia modelos mentais, lugares simbólicos, e representações.

Pensar a filiação pode ser pesquisar o funcionamento das imagens, seus movimentos, as formas de apreensão, o trabalho de representação imaginária, e como a partir desses esquemas se constroem os pertencimentos, as relações dentro das supostas famílias, da suposta comunidade (Noudelmann, 2004, p. 17, tradução nossa).

A representação da infância na obra de Miguel Sanches Neto expõe o processo de naturalização das semelhanças a partir da filiação. $O$ modelo genealógico condiciona o olhar e cristaliza modelos de representação. O menino não tem outro caminho, senão o de perpetuar as características que teria herdado, ainda que não tenha convivido com o pai, porque esse é o papel que ele tem de cumprir. "Filho do pai", decreta a comunidade.

Como no romance de Marcia Tiburi, Chove sobre minha infância também é marcado pela ausência de imagens. "Éramos pobres e não tínhamos o hábito de fotografar. De meu pai, por exemplo, restou apenas o retrato de casamento, o mesmo que está em seu túmulo" (Sanches Neto, 2012, p. 10). O menino busca compensar a impossibilidade de uma identificação física, com a projeção de uma semelhança baseada no temperamento, correspondendo assim à expectativa de herdeiro de um legado previsível.

No esforço de se diferenciar do padrasto, a quem ele chamará de pai, o garoto não percebe o mimetismo que se dá nessa relação, ainda 
que por outro viés. O menino que se recusa a trabalhar na roça como os irmãos, o menino que segue o caminho das letras, sendo filho de pais analfabetos, só terá consciência da profunda identificação com o padrasto anos mais tarde, ao escrever seu primeiro romance, a autoficção Chove sobre minha infância (2012). Só então ele deixará a condição de órfão para reconhecer vínculo e a semelhança com o homem que o criara.

É pelos olhos da irmã, através de uma carta, que o autor narrador entenderá esse processo.

É que você se vale da caneta como uma enxada, numa literatura sem enfeites. Veja só. Você detesta o relógio de pulso, da mesma forma que o pai. Tem vergonha de sair de óculos escuros e de bermuda, assim como o pai. Gosta de levantar cedo, de trabalhar até ver o fim do serviço. Tal padrasto, tal filho. Toda essa herança está na sua maneira de ver a literatura e de escrever. Você é um camponês no meio de civilizados e isso é o reflexo da educação que, ao mesmo tempo contrariado, você herdou do lado mais rústico da sua família (Sanches Neto, 2012, p. 248).

A carta, incluída no final do romance, traz revelações importantes. A principal diz respeito à imagem positiva do pai biológico, que fora fabricada pela mãe. A irmã revela que o pai tivera várias amantes e se envolvera com roubo de café nas fazendas da região. "A mãe sempre fora uma contadora de histórias e soube por a ficção na frente do real" (Sanches Neto, 2012, p. 248), escreve a irmã, acrescentando que a mãe não queria que o filho descobrisse o "lado feio do pai". Esse pai idealizado, no entanto, impediu o garoto de viver bem com o padrasto, descrito na carta como um homem honesto. "Veja como você sempre tem tantos projetos, isso você deve a ele. Me conte, quando você o viu fazendo qualquer coisa desonesta?" (Sanches Neto, 2012, p. 249), questiona a irmã, dizendo-se feliz por finalmente poder revelar esse segredo familiar.

\section{"Ar de família"}

Para Noudelmann (2004) a origem não é uma prova, mas uma construção discursiva. Ele questiona a crença na aparência familiar como uma marca distintiva do sujeito, como se a transmissão biológica fosse sinônimo de transmissão identitária. Com base nas distinções 
propostas pelo teórico, é possível analisar os romances de filiação sob a perspectiva contemporânea, com as novas configurações familiares e afetivas que as narrativas apresentam.

De acordo com tais teorias, a semelhança não está atrelada à transmissão, mas também se forja na criação de uma comunidade afetiva. As semelhanças se dão na relação entre o "eu" e o "outro", dentro de um conjunto. Por essa perspectiva, a narradora de Azul-corvo (2010), na jornada para refazer os passos da mãe e encontrar o pai biológico, formará uma comunidade afetiva com Fernando e Carlos. Três personagens deslocados em um lugar árido, que estabelecem um código familiar próprio, sem laços biológicos.

É o que Noudelmann (2004) chama de "comunidade negativa" ou "comunidade de ausência" que reúnem indivíduos que compartilham um silêncio, uma incompletude, uma insuficiência. Seria uma reunião de excluídos, que permite a multiplicidade de subjetivações. Esse modelo de filiação a uma comunidade não genealógica, ao mesmo tempo que define semelhanças, preserva identidades.

Enquanto busca o pai biológico, a menina Vanja forma com Fernando e Carlos um arranjo familiar próprio. Os três estabelecem uma comunidade em que é possível viver juntos, sendo absolutamente diferentes. Os filósofos Jean-Luc Nancy (1999) e Maurice Blanchot (1995) convergem para uma distinção entre um être-commun e o être-en-commun. No primeiro, a comunidade é concebida como igualdade, em que o "eu" se dispersa no comum; no segundo a singularidade é assegurada, pois significa "estar-em-comum" e não "ser-comum" a todos.

Essa perspectiva de singularidade assegurada na vida comunitária pode ser mais bem compreendida à luz da idiorritima, proposta por Roland Barthes em Viver junto (2003). Ele fala de um viver junto em que cada um mantém o seu ritmo. Mas não o ritmo marcado pelo relógio, o ritmo no sentido repressivo do mundo atual, que sujeita os indivíduos a uma cadência cortante ou a uma implacável regularidade.

Barthes (2003) busca na etimologia da palavra, que vem de rythmós, o significado original: interstícios, fugitividade do código. Já as relações de poder resultam no oposto, na disrritimia/heterorritmia. Para exemplificar, ele utiliza a imagem da mãe que puxa o filho pequeno pelo braço, obrigando-o a andar em um ritmo que não é o seu. Nas comunidades idiorrítmicas, aquelas que não são formadas a partir do 
paradigma genealógico, essa relação de poder desaparece. Cada um pode manter a sua individualidade.

Em algumas passagens de Azul-corvo (2010) essa configuração fica evidente. "Éramos um mundo de compatibilidades, estávamos irmanados, nos equivalíamos - e onde não nos equivalíamos, nos compensávamos" (Lisboa, 2010, p. 157), afirma a narradora sobre o vínculo entre ela, Fernando e Carlos. A personagem descreve essa relação como uma família improvável, multinacional, cheia de línguas diferentes e de sotaques diferentes da mesma língua, com idades e preocupações em tese incompatíveis. E que, no entanto, "ali estavam".

O caminho trilhado por Adriana Lisboa nesse romance desnaturaliza a relação direta entre transmissão genética e aparência familiar. A narradora parte de uma fantasia de menina em relação a sua origem. "Afinal, se as pessoas não me forneciam detalhes, eu tinha todo o direito moral de providencia-los eu mesma" (Lisboa, 2010, p. 45). O encontro com a família biológica, no entanto, romperá com as expetativas iniciais, colocando em xeque a ideia de transmissão genealógica.

François Noudelmann, em Les airs de famille: une philosophie des affinités (2012), introduz um conceito novo sobre semelhança: o "ar de família". Quase indefinível, nem sempre facilmente perceptível. Pode ser um ritmo, um estilo, um temperamento. Designa uma forma que vai além da aparência e singulariza o sujeito.

$\mathrm{O}$ "ar" alivia o peso das semelhanças na dívida familiar, na medida em que não designa uma identidade genealógica, nem uma categoria definitiva. Recusa-se a essencializar as semelhanças. Designa semelhanças efetivas, que derivam de uma relação existente (Noudelmann, 2012, p. 178).

Passar da semelhança genealógica para o "ar de família" exige uma mudança na forma de pensar e de observar. Os corpos, as formas e as relações são vistos dentro de outro prisma que se desvincula de uma continuidade natural e os faz entrar dentro de conexões aleatórias imprevistas. As características da fisionomia têm menos significado do que a gramática dos corpos. Formas de falar, de sorrir, de agir. Imitação de atitudes físicas, de empatia. O mimetismo é como um contágio, que faz os corpos se parecem entre si e que constrói semelhanças reconhecidas como familiares.

Essa teoria ficará evidente no romance de Adriana Lisboa, no momento em que a menina conhece Florence, a avó paterna, que 
desconhecia a existência da neta. Quando o parentesco lhe é revelado, a personagem fita a menina à procura de uma semelhança física.

Claro que Florence procurava Daniel ${ }^{3} \mathrm{em} \mathrm{mim}$. Eu me perguntava se eu também teria o visto na foto do meu passaporte caso o tivesse conhecido, se o teria reencontrado na amálgama genética do meu rosto, ou se a minha mãe não precisava dos homens nem para isso (Lisboa, 2010, p. 190).

A narradora revelará mais tarde que a avó não encontrou nela características físicas familiares e nem "a neta que pediu aos céus". De uma só vez, tanto a ideia de semelhança física quanto a projeção idealizada a partir da herança genética são descartadas. Florence só encontrou algo muito tempo depois, conforme explica Vanja: "um traço qualquer no sorriso, um milímetro de curvatura no lábio, que ela processaria ao longo dos anos seguintes até um dia me dizer, definitiva: você tem o sorriso do seu pai" (Lisboa, 2010, p. 199). É o "ar de família", que não foi perceptível no primeiro contato, confirmando que se trata de uma semelhança construída, estabelecida a partir da convivência.

\section{Conclusão}

As semelhanças construídas são frequentemente mais fortes que as semelhanças biológicas. Daí o interesse em estudar as configurações genealógicas, imaginárias, utópicas, íntimas ou coletivas, como as maneiras novas de conceber as filiações, ou os modelos políticos e sociais que regem as relações de parentesco.

Os romances de filiação são narrativas críticas, na medida em que descontroem o paradigma genealógico e aprofundam os questionamentos identitários. No contexto atual, o questionamento da memória familiar é renovado, incluindo os paradoxos contemporâneos. Através das figuras de ascendência, desenha-se a arqueologia da modernidade, como se a invenção de si mesmo dependesse da solução de enigmas e segredos ocultos no processo de transmissão hereditária.

Os personagens trazem o desejo de romper com a tradição de quebrar o peso das heranças. O silêncio paira sobre o narrador, como um segredo inacessível sobre si mesmo. Ele tenta fazer um balanço de desejos insatisfeitos, de mapear transmissões, os determinismos

\footnotetext{
${ }^{3}$ Daniel é o nome do pai biológico de Vanja.
} 
biológicos, geográficos. Ele inventa uma memória, inspeciona as dobras de sua identidade. O sujeito contemporâneo desafia a herança familiar e a transmissão genealógica. Como se, em vez de um legado, parte da herança fosse a transmissão de uma ausência.

Nos romances de filiação contemporâneos, a linearidade que evidencia infância e morte em polos que orientam a vida é substituída por narrativas fragmentadas. É nessa descontinuidade, naquilo que incomoda os personagens no presente, que reside a necessidade de olhar para o passado, para o tempo da infância, não como alguém que o revisita, mas que precisa resolver pontos obscuros.

Entendendo a filiação como processo, a transmissão deixa de ser concebida como inevitável ou automática para ser entendida como construção. A desconstrução da ideia do determinismo familiar abre a possibilidade de representações identitárias menos restritas e permite estudar maneiras outras de conceber filiações na literatura contemporânea.

\section{Referências}

BARTHES, Roland (2003). Como viver junto. Tradução de Leyla Perrone-Moisés. São Paulo: Martins Fontes.

BLANCHOT, Maurice (1995). L'espace littéraire. Paris: Gallimard.

DEMANZE, Laurent (2008). Encres orphelines. Paris: José Corti.

LISBOA, Adriana (2010). Azul-corvo. Rio de Janeiro: Rocco.

NANCY, Jean-Luc (1999). La communaute désouvréet. 3. ed. Paris: Christinan Bourgois.

NOUDELMANN, François (2004). Pour en finir avec la généalogie. Paris: Léo Scheer.

NOUDELMANN, François (2012). Les airs de famille: une philosophie des affinités. Paris: Gallimard.

ROBERT, Marthe (2007). Romances das origens, origem do romance. Tradução de André Telles. São Paulo: Cosac Naify.

SANCHES NETO, Miguel (2012). Chove sobre minha infância. 2. ed. Rio de Janeiro: Record.

TIBURI, Marcia (2012). Era meu esse rosto. Rio de Janeiro: Record.

VIART, Dominique (2008). La littérature française au présent. 2. ed. Paris: Bordas. 
Recebido em outubro de 2014.

Aprovado em março de 2015.

\title{
resumo/abstract
}

\section{Bastardos e órfãos contemporâneos: a arqueologia da infância nos romances de filiação}

\begin{abstract}
Alessandra Dalva de Souza Pajolla
A reconstituição das origens configura uma dinâmica narrativa presente em diversas obras no campo literário atual: o retorno ao passado despido de nostalgia, marcado pela tentativa de explicar por meio das origens (reais e imaginárias) as lacunas identitárias. Os romances de filiação integram essa tendência e interrogam a ascendência como um mecanismo para resolver enigmas do presente. As obras Azul-corvo (2010), de Adriana Lisboa, Era meu esse rosto (2012), de Marcia Tiburi, e Chove sobre minha infância (2012), de Miguel Sanches Neto, expõem o percurso de narradores que voltam ao tempo da infância em busca de autoconhecimento e, sobretudo, pertencimento.
\end{abstract}

Palavras-chave: romances de filiação, identidade, Adriana Lisboa, Marcia Tiburi, Miguel Sanches Neto.

\section{Contemporary bastards and orphans: an arqueology of childhood in novels of affiliation}

\section{Alessandra Dalva de Souza Pajolla}

The reconstruction of the origins sets up a dynamic narrative present in several books in the contemporary literature: the return to the past, without nostalgia, marked by the attempt to explain identities through their origins (real and imaginary). Novels of affiliation are part of this trend, questioning genealogy as a mechanism to solve the mysteries of the present. The novels Azul-corvo (2010), by Adriana Lisboa, Era meu esse rosto (2012), by Marcia Tiburi, and Chove sobre minha infância (2012), by Miguel Sanches Neto, describe narrators returning to their childhood in search of self-knowledge and especially a sense of belonging.

Keywords: novels of affiliation, identity, Adriana Lisboa, Marcia Tiburi, Miguel Sanches Neto. 